\title{
Ensino técnico-profissional no Brasil e em Portugal na perspectiva da integração regional*
}

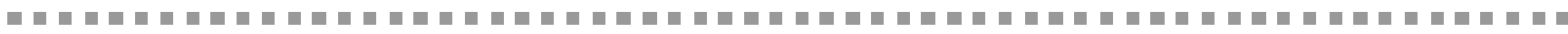
Maria Sylvia Simões Bueno

\author{
Palavras-chave: ensino técnico; \\ ensino profissionalizante; \\ integração regional; reformas \\ de ensino; padrão de gestão.
}

\section{Resumo}

O estudo comparado de questões contemporâneas do ensino técnico-profissional de um país semi periférico (Portugal) e de outro periférico (Brasil), com análise de implicações dessa condição, aponta tendências comuns no encaminhamento de reformas e modelos de gestão, que são verdadeiras vertentes do ideário de organismos de pensamento articulado como a Unesco, União Européia e o Bird, mas se constroem em contextos específicos, nos quais a integração regional se realiza de formas diversas, onde as intencionalidades e a sustentação financeira são protagonistas. Raízes socioculturais profundas entrel açam-se e garantem traços rançosos comuns nesses dois mundos, tais como o paternalismo de Estado e o preconceito contra o trabalho manual; contudo, condições peculiares promovem experiências interessantes para a reflexão acadêmica dos dois países e ensejam a realização de trabal hos cooperativos.

\section{Considerações iniciais}

Estudos comparados, enquanto abordagem metodológica, tornaram-se, nos anos 90, uma temática significativa, tanto pelo alargamento do espaço-temporal trazido pelos processos socioeconômicos gl obalizantes quanto pela sua apropriação nem sempre adequada e muitas vezes oportunista pelas agências internacionais, quando recomendam diretrizes para reformas educativas e modelos de gestão pelo mundo afora. Concepções difusas de identidade, tanto quanto relações verticais entre o eu e o outro, impregnadas pela ideologia do progresso e o ideário econômicodesenvolvimentista dos organismos financeiros, encaminharam - e encaminham -, via de regra, a naturalização de estereótipos e preconceitos, bem como a redução de realidades educacionais diversas a denominadores comuns que ensejam a homogeinização de problemáticas genéricas e soluções "salvadoras".

Novoa (1998, p. 12), com base em diversos autores, ressal ta que a redefinição de identidades nos planos local e internacional, no seio da nova ordem mundial em composição, aponta para a emergência de uma abordagem comparada da educação. Nesse quadro, a comparação facilita a refle xão sobre a "reorganização dos espaços educativos no nível internacional, através de regulações econômicas e políticas que atravessam as fronteiras dos diferentes países" e, ao mesmo tempo, sobre a "presença

\footnotetext{
* O presenteartigo éum dos produtos da pesquisa realizada na dutos da pesquisa realizada na
Universidade do Minho (Uminho), em Portugal, com bolsa de pós-doutorado daFundação de Amparo à Pesquisa do Estado de São Paulo (Fapesp).
} 
crescente das questões educativas na criação de identidades locais". Todavia, esse autor recomenda cuidados especiais em sua adoção, em razão da profusão das práticas comparativas existentes. São eles: a aceitação do outro, a pluralidade de significados e a compreensão dos seus limites de interpretação.

O estudo comparado de políticas e reformas educativas de um país semi periférico (Portugal) e outro periférico (Brasil), juntamente com a análise das implicações principais dessa condição, permite observar que, embora as tendências no encaminhamento de reformas emodel os de gestão para o ensino técnico profissional sejam assemel hadas nos dois países, no caso do ensino técnico-profissional desenvolvem-se em contextos diversos, a integração regional real iza-se (ou tropeça) em desenhos muito diferenciados, e as intencionalidades e a sustentação financeira exercem um papel protagônico. Mesmo que raízes socioculturais antigas e profundas se entrelacem e garantam traços rançosos comuns a esses dois mundos, tais como o paternal ismo de Estado e o preconcei to contra o trabal ho manual, condições peculiares promovem experiências interessantes para a reflexão acadêmica nos dois países.

Stöer e Cortezão, em seu livro Levantando a pedra (1999), fazem uma introdução metafórica bastante estimulante, na qual apresentam o conteúdo da obra ejustificam seu título. Referem-se os autores à paisagem marinha oferecida pela maré vazante, com a emergência de pedras e rochas revestidas de musgos, algas e pequenos animais, numa aparência de eterna permanência no tempo e no espaço, em sua úmida tranqüilidade e segurança. Porém, se alguém ousar, durante uma caminhada pela praia, revirar essas pedras ou levantar uma das rochas menores, um mundo novo será revelado. Um mundo insuspeitado de turbulências fervilhantes de vida, feitas de coexistências, partilhas, conflitos, de lutas pelo domínio de espaços, de sobrevivência, de poder. O sobressalto, sem dúvida, será maior para al guém que construiu, para si próprio, a idéia de que a pedra não pode, não deve, ser mais do que aquilo que revela na superfície musgosa ou coberta de algas que expõe à luz do dia. No entanto, esse desvelamento, para al ém da aparência imediata, pode mostrar a mesma realidade em outras perspectivas e ampliar o poder de compreensão sobre suas múltiplas faces.
Ao passear os olhos sobre a paisagem oferecida pelos textos rasos, desenraizados e pretensamente objetivos, comumente oferecidos pelas agências internacionais (incluídas a Unesco e União Européia), temos a tentação de compor cenários homogêneos ou tecer quadros de semelhanças e diferenças que podem induzir à replicação de imagens que, como na arte, sempre serão réplicas e, como tal, fal sas e perigosas.

Perquirir a complexidade do insuspeitado que se oculta sob rotinas e figuras oficialmente construídas, desocultar os processos que sob elas se tecem é uma empreitada difícil e vai exigir, sem dúvida, um intenso trabal ho cooperativo de experts de contextos comparáveis, em estreita colaboração. Nesses termos, o presente artigo não vai além de um início de conversa, de uma provocação.

\section{Idéias de integração}

De acordo com Bobbio (1993, p. 632), "integração, lato sensu, significa a superação das divisões e rupturas e a união orgânica entre os membros de uma organização." A regra tradicional contempla o Estado-Nação como centro desse processo ou condição (perspectivas sob as quais a integração pode ser considerada). Atualmente, a abordagem da integração extrapola espaços nacionais, numa ótica de reorganização territorial. Na União Européia está em processo o redimensionamento do Estado, a construção de um Estado Europeu, que sinal iza para um conjunto de propósi tos, instituições e ações comuns que incluem a moeda, políticas nas mais diversas áreas como a educacional -, e organismos, como o Parlamento Europeu, a Corte de Justiça, a Comissão Européia e o Conselho Europeu.

No bojo desses esforços de integração, considerando o patamar de importância adquirido pelo ensino secundário na Europa contemporânea, a produção intelectual e a experiência portuguesa, adquirida em suas recentes reformas educativas, incorporando algumas tendências globais - entre as quais figura até mesmo a idéia de um sistema mundial de educação -, têm-se empenhado na área do ensino técnico-profissional eproduzido iniciativas e estudos importantes para a reflexão de todos os envolvidos com as reformas em andamento no setor. 
Antunes (1999, p. 399) assinala que a anál ise de documentos produzidos e divulgados nos últimos 20 anos, no contexto da Comunidade Européia, "parece fundamentar a expectativa de que é possível identificar a construção e afirmação de entendimentos, orientações e referências gl obais comuns capazes de inspirar e modelar a intervenção política pública no campo educativo". A referida pesquisadora identifica esse processo convergente como um mecanismo de europeização que, no caso do ensino e formação profissional, orienta-se por alguns vetores básicos, tais como a inserção na vida ativa, a ação escolar como promotora de interfaces institucionais e a consideração do setor privado como "locus de produção do bem comum".

Antunes (1999, p. 370) esclarece, ainda, o significado desses vetores, fortemente imbricados entre si, sem dúvida referenciados ao ideário hegemônico que desloca o mercado para o núcleo estruturador da sociedade. Nessa perspectiva, mostra que a idéia de inserção na vida ativa, dimensionada em meados dos anos 70 como momento de passagem dos jovens da educação escolar para a vida adulta e profissional, tendo por pano de fundo as perspectivas de crescente desemprego, recompõe-se, nos anos 90, como um período de transição muito mais complexo, pois implica, além de um alargamento que se inicia dentro da escola e se prolonga para além dela, sua redefinição como 'traço estrutural mais permanente das trajetórias profissionais e sociais dos indivíduos (...). A formação ao longo da vida acaba por adquirir também (ou sobretudo) o sentido da natural ização da expectativa (ou possi bilidade) da transição ou transitoriedade ao longo de toda a vida profissional". Esse ajuste aos modelos de reestruturação produtiva flexível redimensiona o ensino e a formação de nível secundário, em todas as suas modalidades, em "plataforma giratória para toda uma vida" (Unesco, 1998, p. 134).

A transição para a vida ativa é o eixo articulador da escola profissional portuguesa e orienta seu modelo de gestão enquanto espaço promotor de interfaces institucionais, aberto e integrado aos diversos contextos locais. O setor produtivo, secundarizado pelas câmaras municipais, é privilegiado em acordos que estabelecem protocolos de cooperação, colaboração e parcerias (paternariados).
Com respeito à gestão, a articulação de parcei ros locais coloca ênfase na autonomia, para além da tradicional associação entre descentral ização e democracia, numa dimensão que vai permitir, entre outros mecanismos, a "mestiçagem" do público com o privado, a mai or adaptação a mudanças e a anteci pação da convivência com elementos característicos da produção flexibilizada, tais como a ambi güidade, a mobilidade e a transitoriedade. Compõe-se, dessa forma, uma nova racionalidade para o ensino técnicoprofissional, no quadro da integração européia, assimilado em território português pela via das novas escolas profissionais.

Contudo, se é possível a Portugal, pela sua posição geográfica privil egiada e grau de integração da União Européia, funcionar como balcão para o mundo desenvolvido, mantendo contato mais direto com experiências bem e malsucedidas e com as reações que provocam nos países de origem, o Brasil, dada sua grande diversificação interna, permite um caleidoscópio de experiências a partir de uma matriz, mesmo que ela seja uma receita imposta por uma agência financeira, cuja análise crítica pode oferecer sustentação sóli da para propostas nacionais, bem como material de reflexão para pesquisadores e fazedores de política de outros países.

Um cuidado a observar é que o Brasil está envolvido em tentativas de integração que vão de iniciativas mais abrangentes, orquestradas por agências internacionais, até o caso específico do Mercosul, de certo modo espelhado na experiência européia e centrado numa articulação de forças regionais que pretende contribuir para a construção de um cenário mundial multipolar, no qual sua possi bilidade de inserção substantiva se efetive. Essas tentativas tropeçam numa série de barreiras e desencontros entre os quais o temor quanto a uma possível aspiração de liderança brasileira, reforçado por al guns deslizes diplomáticos - que têm provocado reações devidas e indevidas de seus parceiros e fragilizado, de certo modo, o comportamento cooperativo.

Um ol har sobre as rel ações latino-americanas permite vislumbrar, além de relações econômicas obscuras, experiências educacionais incipientes que, al ém de poucos casos exemplares, dignos de nota, expressam-se em articulações acadêmi cas que não atingem a dinâmica dos sistemas escolares e, muito menos, o ensino técnico-profissional. Similaridades decorrem muito 
mais de agendas comuns concertadas em outras instâncias, monitoradas, via de regra, por organismos financeiros multilaterais.

A intensificação de transações internacionais orientadas pela idéia de desterritorialização econômica, política e cultural, além da fascinação das miragens de integração e compartilhamento fácil das benesses da "sociedade global", com superval orização de model os bem-sucedidos nos países centrais, articula vetores para reformas educativas: desafios econômicos, posi ção geoeconômica e geopolítica no sistema internacional estruturado em função do poder do conhecimento...

Nesse panorama, países mais desenvolvidos que empreenderam mudanças relevantes em áreas educativas consideradas estratégicas, como o ensino técnico-profissional, servem de base para inovações em países identificados como atrasados eemergentes. Argumentos e soluções globais são incorporados sem cautela e se desconsidera o fato de que condições para o florescimento de uma idéia ou ação em um país podem ser inócuas ou não existir em outro país. A redução sociológica que acompanha essa transferência acrítica costuma envolver, ainda, o uso de categorias como descentralização, participação, autonomia, ação comunitária, parcerias, inserção, territorialidade, etc., sem a devida explicitação conceitual, promovendo dubiedades e facilitando manipulações.

No quadro de processos diferenciados de integração, mas seguindo diretrizes assemelhadas, Brasil e Portugal, na última década, encaminharam a construção de sistemas diversificados e paralelos de formação técnico-profissional. Na agenda de ambos os países, figura a descentralização como ponta de lança da transformação, associada a novas formas de relação entre o público e o privado e à criação de localismos garantidores de maior envolvimento da sociedade civil.

Todavia, múltiplas dimensões e relações entre conjuntos de determinantes culturais, sociais e históricas - difíceis de especificar e medir - ultrapassam possibilidades comparativas e não recomendam paral elismos sem que se resvale para leituras superficiais das paisagens oferecidas. A opção, nesse caso, é considerar em separado as duas situações e deixar reflexões mais aprofundadas para um trabaIho cooperativo.

\section{Reformas educacionais no Brasil dos anos 90 e o ensino técnico- profissional}

A organização do ensino técnico-profissional no Brasil percorre uma longa via secundária, por conta de sua quase-segregação aos "desvalidos da sorte" e de uma história de cooperação estrangeira, via acordos com agências internacionais. As distorções do sistema incomodaram os educadores desde a década de 30, a ponto de Anísio Teixeira, em sua passagem pela Secretaria da Educação e Cultura do Distrito Federal, então no Rio de Janeiro, implementar medidas integradoras no ensino médio - infelizmente efêmeras - que se antecipavam aos planos europeus.

Várias tentativas de rompi mento com a dualidade culminaram com a "profissionalização ilusória delirante" dos anos 70, que se arrastou até a década seguinte, quando a escola média reassumiu seu caráter indefinido na forma e el itista no sentido.

A "profissional ização flexível" atinge o sistema de escolas profissionais em meados dos anos 90, orquestrada por acordos financeiros multilaterais, e assume um caráter totalmente descolado do sistema regular, a ponto de concentrar-se apenas na formação específica. No ensino médio, salvo pinceladas de informatização, ainda é irrel evante, na real idade escolar, o componente tecnológico. Aprofunda-se, nesses termos, a dicotomia do sistema, com alargamento da fragmentação, em função das propostas de justaposição curricular e do acoplamento de módulos sem qualquer previsão de alteração dos tempos e movimentos da organização escolar tradicional.

O grande paradoxo é que a educação profissional, tendo como pano de fundo a sociedade tecnológica e do conhecimento do novo milênio, dá status de escolarização formal a cursos que sempre vegetaram na informal idade. Real ismo econômico-pedagógico? Ou conformação a um modelo de inserção adjetiva num cenário de rarefação do trabal ho formal?

Em meio a uma atuação controvertida dos sindicatos e organizações patronais, foi desencadeada uma corrida pelas parcerias, mediante convênios um tanto nebulosos e, muitas vezes, de caráter duvidoso, ao sabor de políticas locais e do voluntarismo 
empresarial. As balizas discursivas para a gestão escolar são a autonomia, a participação comunitária e a ação colegiada. Todavia, os col egi ados e articulações tendem a ser frágeis ou inexistentes. O Centro Paula Souza do Estado de São Paulo, por exemplo, organizado como fundação para garantir maior agilidade eliberdade de movimentos, al ém de adotar claramente o "novo gerenciamento educacional", decalcado da empresa, conta com consel hos de escola em menos da metade das suas unidades, $30 \%$ dos quais funcionando com regularidade, embora com representação comunitária questionável (dados de 2000).

\section{0 sistema educativo português na década de 90 e as novas escolas profissionais}

A Lei de Bases do Sistema Educativo de meados dos anos 80 , vinda após décadas de central ismo, previu a autonomia das coletividades locais e a descentralização democrática da administração pública lusitana.

Em termos de diretrizes legais (tal qual no Brasil), a educação tecnológica, enquanto temática transversal, é um dos principais eixos da vasta reforma do sistema educativo português. Portugal insere-se, nesse caso, no movimento de progressiva integração curricular e institucional entre as vias de formação profissional e as vias de formação geral e de concomitante desespecialização nas tradicionais vias técnicas e profissionais (lógica educacional seguida no mundo desenvolvido e refletida no mundo subalterno).

O denominado ensino secundário superior em Portugal, regulamentado em 1989, reestruturado concretamente apenas a partir de 1993 e generalizado no último quinqüênio dos anos 90 , traduz um reordenamento do ensino pós-obrigatório que atribui aos diferentes diplomas (geral, tecnológico e profissional) o acesso ao ensino superior. Todos os cursos têm as componentes geral, científica e técnica, com ampliação substantiva da componente geral nos cursos técnicos e redução expressiva das especializações técnicas. Nessa constelação, o sistema paral el o - mas não desintegrado - das novas escolas profissionais, "liberado dos arcaísmos e ranços do sistema tradicional", exprime rumos inovadores e fl exíveis da educação escolar e oferece uma formação alternativa e equival ente ao secundário superior. Situação muito diferente da brasileira, onde o sistema de educação profissional isola-se do sistema regular e somente a ele se articula via voluntarismo discente.

Todavia, por razões bastanteassemelhadas às brasileiras, ressaltadas por vários estudiosos, dentre os quais Silva (1996, p. 14), o sistema educativo português menosprezou e menospreza profundamente a educação técnica e tecnológica. Preval ece, no cenário escolar, segundo esse autor, uma "combina ção perversa entre hiperval orização discursiva e desval orização efetiva que só será superada se a dimensão tecnológica atingir a globalidade do sistema." Essa ótica se expressa na hierarquia das passarelas percorridas ao final dos anos 90 pelos jovens: curso geral voltado para a continuidade de estudos (63\%); curso tecnológico que dá acesso ao ensino superior, mas se orienta pelo mercado (28\%) e escola profissional resultante de parcerias comunidade/forças vivas locais/Estado (9\%).

As duas primeiras al ternativas são oferecidas pela rede pública comum e parecem ser as mais impregnadas pelos velhos modelos, traduzidos em artificialismos de ordem administrativa e curricular, como por exemplo: divisão sexista das escolas (o que inclui opções curriculares); formalismos na gestão participativa (predomínio do triunvirato diretivo sobre o consel ho deliberativo ou individualismo autoritário, às vezes decorrente da intervenção de instâncias superiores) e na elaboração de projetos pedagógi cos; indefinição incômoda da componente educação tecnológica (sua dimensão transversal praticamente inexiste). Esse quadro oferece, como no caso brasileiro, em que pesem as injeções financeiras da União Européia em países semiperiféricos, a triste sensação de que as reformas só existem no papel.

O sistema de escol as profissionais, bastante diversificado, flexível e diferenciado, pretende concentrar-se na 'transição para a vida ativa", discutida no início do texto eé, sem dúvida, o espaço al argado de inovação da escola portuguesa quer em termos de gestão participativa, quer em termos de organização e funcionamento (com grande flexibilidade de tempos e movimentos), quer em termos de organização curricular. 
Mesmo essa alternativa, caracterizada como nova construção fora do sistema tradicional, sofre com al guns traços arraigados, tais como: tendências à centralização, gestão personalista, parcerias reduzidas à gestão privada do dinheiro público e pouco preocupadas com a dimensão pedagógica, receptividade dúbia dos empregadores elocal ismo político. Esses traços costumam aparecer associados a certas ingenuidades, tais como considerar os "homens de negócio" como clientes-decisores dotados de omnisciência e imaculada legitimidade social esantificar os parcei ros comunitários a ponto de criar impasses patrimoniais.

\section{Considerações finais}

A reflexão mais detida sobre as experiências aqui esboçadas, guardadas as devidas proporções e diferenças entre as duas situações, no caso brasileiro, pode servir de referência para os tateantes projetos nacionais, enquanto há tempo deredirecionálos. A vel ha prática de tentar recortar projetos de dez mil dólares para cem dólares (custo/aluno) na onda da importação e experimentação de modelos, precisa ser questionada. O referencial teórico dos referidos modelos, quando recomendados por organismos multilaterais, costuma ser a análise econômica, a teoria empresarial e uma nova versão da teoria do capital humano, recomendadas pelos organismos internacionais, como eles mesmos assumem. É necessário, na área do ensino médio e da educação profissional, que se considere, como problemática principal a ser atalhada, a questão social brasileira expressada no aumento das assi metrias sociais (desigual dade), na ausência de diál ogo e no consenso induzido (autoritarismo), no desrespeito/ausência de direitos (exploração) e na redução da cidadania aos limites da produção/consumo (exclusão). Uma proposta educacional assim orientada constrói novos desafios para os estudiosos.

\section{Referências bibliográficas}

ANTUNES, F. A transição da escola para a vida ativa e a redefinição da educação no contexto da integração européia. Investigar e Formar em Educação, Porto, v. 1/2, 1999.

BOBBIO, N. Dicionário de Política. 5. ed. Brasília: Edunb, 1993.

BUENO, M. S. S. Políticas atuais para o ensino médio. Campinas: Papirus, 2000.

Relatório de Pesquisa "Gestão do Ensino Médio e da Educação Profissional na perspectiva da Integração Regional". Marília: Unesp, 2002.

CETESP Paula Souza. Observatório Escolar 2000. Cópia impressa.

COWEN, R. Last past the post: comparative education, modernity and perhaps post modernity. Comparative Education, v. 32, n. 2, 1996.

CUNHA, L. A. O ensino profissional na irradiação do industrialismo. São Paulo: Unesp, 2000.

E. P. Bento de Jesus Caraça Projecto Educativo/versão final. Jornadas Pedagógicas 2000. Cópia impressa.

NOVOA, A. Histoire \& Comparison. Lisbonne: Educa, 1998.

RODRIGUES, J. C. Contributos das E.P.s do interior no desenvolvimento regional. Trancoso, 2000. Cópia impressa.

SILVA, J. M. (Org.). Avaliação do Sistema de Escolas Profissionais. Lisboa: ME, 1996.

STÖER, S. R.; CORTEZÃO, L. Levantando a pedra. Porto: Edições Afrontamento, 1999.

UNESCO. Educação, um tesouro a descobrir. São Paulo: Cortez; Brasília: MEC, Unesco, 1998. 
Maria Sylvia Simões Bueno, doutora pelo Programa de Pós-Graduação em Educação da Faculdade de Filosofia e Ciências de Marília/Universidade Estadual Paulista (Unesp), é professora-assistente do Departamento de Supervisão e Admi nistração Escolar e do referido Programa de Pós-Gradução, e líder do grupo "Estudos e Pesquisas sobre Política Educacional Brasileira".

msylvia@flash.tv.br

\section{Abstract}

The comparative study on contemporary issues of technical/professional education of a semi-peripheral country (Portugal) and of a peripheral one (Brazil), with analyses of the implications of this condition, points to common trends on the implementation of reforms and management models, which are true vehicles of the thinking of organisms such as Unesco, EU and Bird, but are built in specific contexts, in which the regional integration is made by diverse ways, where the intentional acts and the financial support are protagonists. Crossed, deep social and cultural roots guarantee common old tracks in these two worlds, such as state paternalism and prejudice against manual work; however, specific conditions promote interesting experiences for academic reflection in both countries and allow them to carry on cooperative pieces of work.

Keywords: technical/professional education; regional integration; educational reforms; management models; comparison.

Recebido em 29 de agosto de 2003.

A provado em 5 de setembro de 2003. 